\title{
有害大気污染物質対策における低温プラズマ法の 応用之研究課題*
}

\author{
尾形敦*1
}

（受理2002年11月25日，掲載决定2003年 3 月 1 日）

\begin{abstract}
Advanced Nonthermal Plasma Technology for the Removal of Dilute Volatile Organic Compounds
\end{abstract}

\section{Atsushı OGATA}

Institute for Environmental Management Technology, National Institute of Advanced Industrial Science and Technology

(Recelved Movember 25, 2002, Accepted March 1, 2003)

\section{1 はしめに}

揮発性有機化合物か環境に与光る影響か明らかになっ てくるとともに，これまて規制対象となっていなかった 物質や排出源住対しても, 規制か求められることか予想 される その場合, これまて確立している焼却佉, 触媒 燃焼去, 吸着法等の技術たけては対応てきないケースも 想定されるため，これらを代替あるいは補ら技術の一つ として低温 (非平衡) プラスマ法か住目されている1-12) 既に, 臭気程度の低濃度 $(\mathrm{ppb})$ の化学物質関しては, 低温プラスマ法を応用した技術か数多く実用化されてい るか, 数十から数百 $\mathrm{ppm}$ の化学物質に対しては, 依然 として電力効率や二次有害副生成物等の課題か残されて おり，優れた方法か確立していない

本稿ては，揮発性有機化合物（VOCs）対策にのみ解 説の対象を絞り，はしめにこの対策技術として研究され ている常温 常圧条件て操作可能な低温プラスマ法を簡 単に説明したのち, 当研究クループて行ってきたパ,ク トー, ト式反応器を用いた芳香族炭化水素の分解反応の 結果を中心低温プラスマ反応の特徴と問題点, またこ れを解决するための研究動向や方向性について紹介す る

\footnotetext{
* 平成14年10月18日 第43回真空に関する連合講演会て講佇

*1 独立行政去人 産業技術総合研究所 環境管理研究部門 (示305-8569 茨城県つくは市小野川16-1 つくはセノター西）
}

\section{2 各種低温プラズマ発生方式}

低温プラスマ佉の中ても常温 常圧下て用いることの てきる手法は限られている 反応器や放電方式の違いに より, VOCs 処理ては主に䛇面放電, 無声放電, パ,ク トへ，卜式放電，パルス放電等か用いられている それ それの放電方式の概要を以下に示すなお，同し放電方 式ても複数の構造の反応器か報告されてお招り, この詳細 については他の解説て紹介されているのてそちらを参照 されたい、10-17)

・玿面放電 セラミ,ク中に埋め込まれた接地電極と七 ラ: ク 上に配した線状電極間に数キロへルノの高周 波電圧を印加し放電させることにより，線状電極の周 囲のセラ:，ク表面沿ってプラスマを発生させる

・無声放電 片側あるいは両側に適当な誘電体（カラス なと）を挿入した電極間に高周波電圧を加え，プラス マを発生させる

・パ，クトへ，卜式放電 ${ }^{11)}$ 強誘電体ペレ，卜を電極間 に充填し，交流高電圧を印加することにより，ペレ， 卜間の空隙全体をプラスマ化させる

・パルス放電 反応器の形態よりも電佰に特徵のある力 去て, 電極間飞立ち上かり時間数十 $\mathrm{ns}$, 持続時間 1 $\mu \mathrm{s}$ 以下の直梳パルス高電圧を印加することて放電電 極からストリーマー放電を発生させ, 電極間の広い範 囲をプラスマ化させる 
Table 1 Reported decomposition rate of various volatile organic compounds by nonthermal plasma

\begin{tabular}{|c|c|c|c|}
\hline Volatile organic compounds & Formula & Concentration & Decomposition rate \\
\hline Methane & $\mathrm{CH}_{4}$ & $113-1000 \mathrm{ppm}$ & $15-90 \%$ \\
\hline Methanol & $\mathrm{CH}_{3} \mathrm{OH}$ & $400 \mathrm{ppm}$ & $95 \%$ \\
\hline Formaldehyde & $\mathrm{HCHO}$ & $40-100 \mathrm{ppm}$ & $97 \%$ \\
\hline Ethane & $\mathrm{C}_{2} \mathrm{H}_{6}$ & $1000 \mathrm{ppm}$ & $51 \%$ \\
\hline Ethylene & $\mathrm{C}_{2} \mathrm{H}_{4}$ & $1000 \mathrm{ppm}$ & $96 \%$ \\
\hline Acetaldehyde & $\mathrm{CH}_{3} \mathrm{CHO}$ & 5-282 ppm & $100 \%$ \\
\hline Acetone & $\mathrm{CH}_{3} \mathrm{COCH}_{3}$ & $100-20000 \mathrm{ppm}$ & $99 \%$ \\
\hline 2-Propanol & $\mathrm{C}_{3} \mathrm{H}_{7} \mathrm{OH}$ & $100-1000 \mathrm{ppm}$ & $99 \%$ \\
\hline Butane & $\mathrm{C}_{4} \mathrm{H}_{10}$ & $1000 \mathrm{ppm}$ & $58-90 \%$ \\
\hline Methylacetate & $\mathrm{CH}_{3} \mathrm{COOCH}_{3}$ & 1000 ppm & $50-95 \%$ \\
\hline Methylethylketone & $\mathrm{CH}_{3} \mathrm{OC}_{2} \mathrm{H}_{5}$ & 113 ppm & $85 \%$ \\
\hline Ethylacetate & $\mathrm{CH}_{3} \mathrm{COOC}_{2} \mathrm{H}_{5}$ & $1000 \mathrm{ppm}$ & $50-80 \%$ \\
\hline Butylacetate & $\mathrm{CH}_{3} \mathrm{COOC}_{4} \mathrm{H}_{9}$ & $1000 \mathrm{ppm}$ & $70 \%$ \\
\hline Hexane & $\mathrm{C}_{6} \mathrm{H}_{14}$ & $113 \mathrm{ppm}$ & $55 \%$ \\
\hline cyclo-Hexane & $\mathrm{C}_{6} \mathrm{H}_{12}$ & 113 ppm & $65 \%$ \\
\hline Hexene & $\mathrm{C}_{6} \mathrm{H}_{12}$ & 113 ppm & $95 \%$ \\
\hline Benzene & $\mathrm{C}_{6} \mathrm{H}_{6}$ & $10-650 \mathrm{ppm}$ & $98-100 \%$ \\
\hline Toluene & $\mathrm{C}_{6} \mathrm{H}_{5} \mathrm{CH}_{3}$ & 60-2000 ppm & $36-100 \%$ \\
\hline Xylene $\left(\mathrm{o}^{-}, \mathrm{m}^{-}, \mathrm{p}^{-}\right)$ & $\mathrm{C}_{6} \mathrm{H}_{5}\left(\mathrm{CH}_{3}\right)_{2}$ & 2-200 ppm & $100 \%$ \\
\hline Ethyl benzene & $\mathrm{C}_{6} \mathrm{H}_{5} \mathrm{C}_{2} \mathrm{H}_{5}$ & $0.2 \mathrm{ppm}$ & $100 \%$ \\
\hline Styrene & $\mathrm{C}_{6} \mathrm{H}_{5} \mathrm{C}_{2} \mathrm{H}_{3}$ & $1000-5370 \mathrm{ppm}$ & $>90 \%$ \\
\hline Bromomethane & $\mathrm{CH}_{3} \mathrm{Br}$ & $1000 \mathrm{ppm}$ & $100 \%$ \\
\hline Tetrachloromethane & $\mathrm{CCl}_{4}$ & $200-3000 \mathrm{ppm}$ & $60-100 \%$ \\
\hline Dichloromethane & $\mathrm{CH}_{2} \mathrm{Cl}_{2}$ & $1000 \mathrm{ppm}$ & $60-99 \%$ \\
\hline Chlorodifluoromethane & $\mathrm{CHClF}_{2}$ & 200 ppm & $90 \%$ \\
\hline Dichlorodifluoromethane & $\mathrm{CCl}_{2} \mathrm{~F}_{2}$ & $1000 \mathrm{ppm}$ & $90 \%$ \\
\hline Chlorotrifluoromethane & $\mathrm{CCIF}_{3}$ & $200 \mathrm{ppm}$ & $85 \%$ \\
\hline Trifluoromethane & $\mathrm{CHF}_{3}$ & $200 \mathrm{ppm}$ & $80 \%$ \\
\hline Tetrafluoromethane & $\mathrm{CF}_{4}$ & $1000 \mathrm{ppm}$ & $32-70 \%$ \\
\hline Dichloroethane & $\mathrm{C}_{2} \mathrm{H}_{4} \mathrm{Cl}_{2}$ & $1000 \mathrm{ppm}$ & $99 \%$ \\
\hline Trichloroethane & $\mathrm{C}_{2} \mathrm{H}_{3} \mathrm{Cl}_{3}$ & $450-1000 \mathrm{ppm}$ & $90 \%$ \\
\hline Trichloroethylene & $\mathrm{C}_{2} \mathrm{HCl}_{3}$ & 50-23000 ppm & $90-100 \%$ \\
\hline Tetrachloroethylene & $\mathrm{C}_{2} \mathrm{Cl}_{4}$ & $100-1000 \mathrm{ppm}$ & $99 \%$ \\
\hline Trichlorotrifluoroethane & $\mathrm{C}_{2} \mathrm{Cl}_{3} \mathrm{~F}_{3}$ & $1000-10000 \mathrm{ppm}$ & $90-100 \%$ \\
\hline Chloropentafluoroethane & $\mathrm{C}_{2} \mathrm{ClF}_{5}$ & 200 ppm & $100 \%$ \\
\hline Hexafluoroethane & $\mathrm{C}_{2} \mathrm{~F}_{6}$ & $1750-3000 \mathrm{ppm}$ & $66 \%$ \\
\hline
\end{tabular}




\section{3. 低温プラズマ法の課題と解決策の模索}

先にあげた低温プラズマ法を用いて，様々なVOCs の分解反応が調べられており，Table 1 亿示すように同 手法はいずれに対しても高い分解能力を示すことが報告 されている。しかし，この技術を実用化するためには， いくつかの課題を解決しなければならない，例えば，生 成物関しては，炭化水素の場合，汪とんどが CO と $\mathrm{CO}_{2}$ 亿酸化分解されるが, 一部の反応器や酸素濃度の 低い反応条件，あるいは八ロゲンを含むVOCsの分解 では反応器前後の炭素の物質収支が合わず，粒子状物質 の生成, 反応器内部へのタール付着, あるいは炭素析出 が報告されている1,2)，特に，八ロゲン系では，除去さ れた VOCs から様々な有害生成物が発生する $3,4,6-8)$.さ らに，バックグラウンドガスに空気を用いているので， 反応条件によっては $\mathrm{O}_{2}$ と $\mathrm{N}_{2}$ の放電副生物として $\mathrm{NOx}$, $\mathrm{N}_{2} \mathrm{O}, \mathrm{O}_{3}$ が観測されている ${ }^{9)}$. 現在, これらを解決する ために様々な試みがなされて抢り，その流れは以下の二 つに大別できる。

\section{1 プラズマ操作条件の最適化}

一つは, 反応器, 電源, 反応条件等のプラズマ操作条 件の最適化である。これまでの報告では互いに反応条件 （対象ガス，流速，共存ガスの影響など）が同じとは限 らないため, それぞれの長所，短所を同一の基準で比較 できるほどの情報は得られていない，特に，分解効率の 向上に重点が置かれてきたため, 副生成物, 放電生成物 についての解析が充分とは言えないケースもあり，単純 飞分解効率だけで環境対策技術としての有用性を判断で さない状況にある。

このプラズマ操作条件の最適化が極めて重要であるこ とを, 最も系統的に調べられているパックトベッド反応 器に打数実験結果を例に紹介寸る。

3.1.1 反応器に充填する誘電材料の違いによる影響9) パックドベッド反応器（Fig. 1 (a)：SUS）では, 充填 材料（組成，誘電率）あるいは印加する交流周波数を変 えることによって，放電条件の制御が可能である，とこ で, 誘電率 (比誘電率) が異なる種々の強誘電材料を反 応器に充填し、ベンゼンの分解を行ったときの結果を

Fig. 2 亿示す. 誘電率によって分解性能に大きな違いが 表れていることがわかる。一般に，誘電率が高い誘電材 料は低いものに比べ電力効率は高いが，一定 $(1,100)$ 以上の誘電率を持つものではほぼ同じ（高い）電力効率 が得られる。竜た，NOxの発生については誘電率が高 くなるほど多くなり，NOxの抑制には低い誘電率の材 料が適しているが，低くなりすぎると $\mathrm{O}_{3}$ の発生を伴う ことになる。

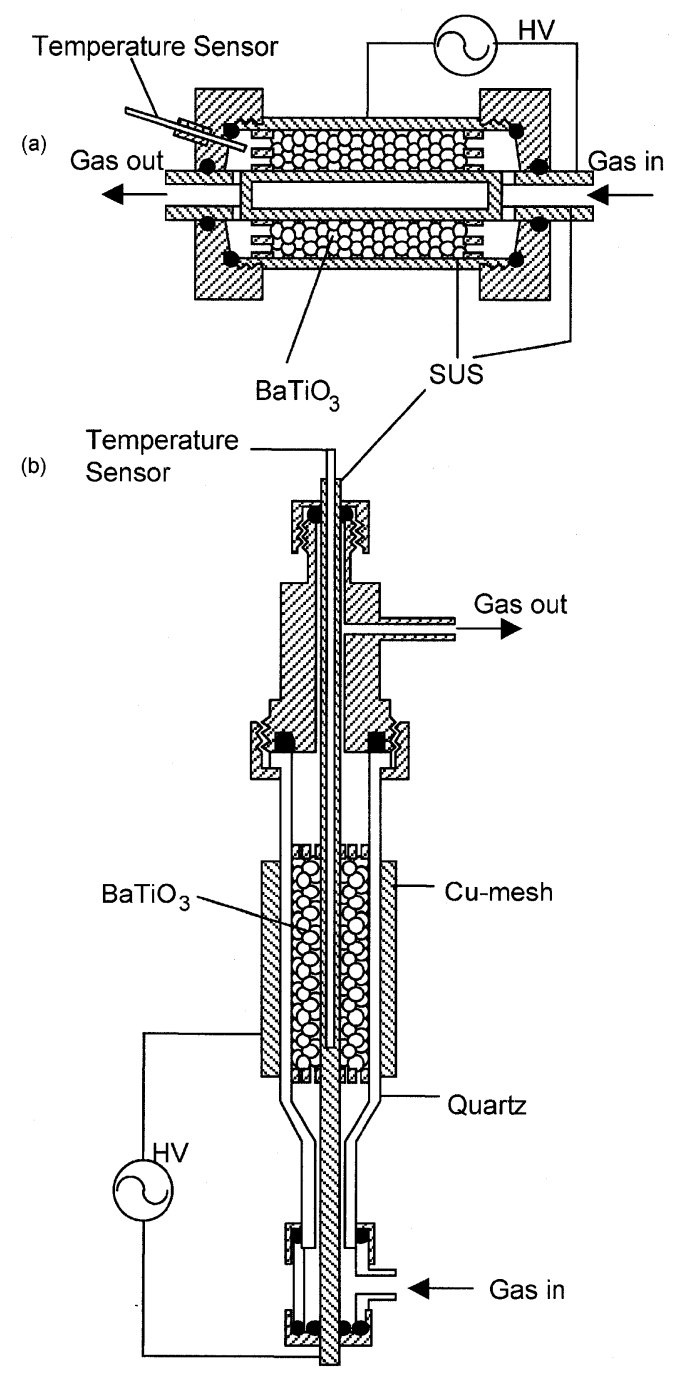

Fig. 1 Configuration of (a) SUS and (b) GL reactors packed with $\mathrm{BaTiO}_{3}$ pellets.

3.1 .2 反応器の構造（放電方式）の違いによる影響18 次に，放電方式が反応特性に与兄る影響について，同 じ反応条件で比較・検討を行った結果を紹介寸る，比較 には, 従来型のパックトベッド反応器 (SUS) と外部電 極の内側にガラス管を挿入した構造の反応器（Fig. 1 （b）：GL）を用いたどちらも強誘電体を充填している が，後者では強誘電体の特性が注とんど活かされて括ら ず, 実質的には無声放電が生じている，この異なる放電 方式の反応器を用いたベンゼンの分解率は, 両反応器で 2 割程度の違いしかみられなかったが，生成物や放電副 生成物については極めて対照的な結果が得られた。両反 応器でベンゼンの分解を行ったときの $\mathrm{O}_{3}$ と NOx の発 


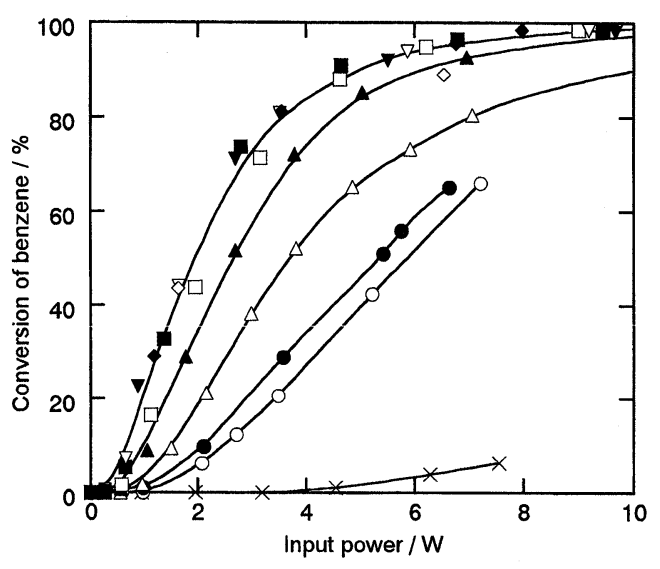

Ferroelectric constants

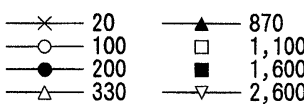

$\begin{array}{ll}\nabla & 4,000 \\ \diamond & 10,000\end{array}$

$\rightarrow \quad 15,000$

Fig. 2 Effect of relative dielectric constant on the plasma system. The relationship between benzene conversion and applied electrical energy.

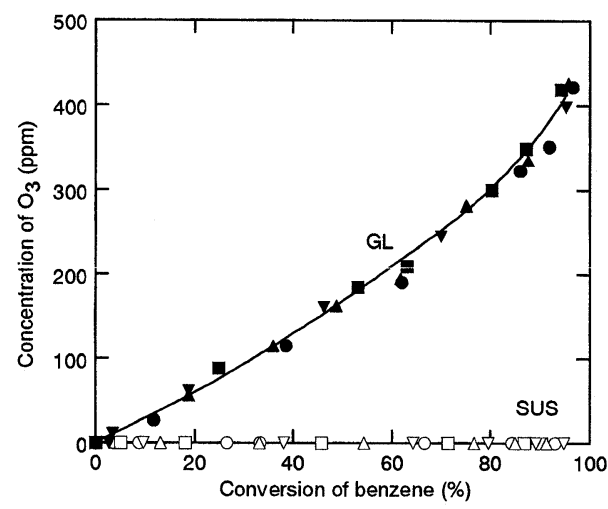

Fig. 3 Behavior of $\mathrm{O}_{3}$ formation as a function of benzene conversion.

生挙動をFigs. 3 と 4 亿示す。これらの図から明らかな ように，同じベンゼン分解率で比較すると前者では NOxが多く発生し， $\mathrm{O}_{3}$ は泀とんぞ検出されていない。 一方, 後者では $\mathrm{NOx}$ はほとんど検出されないが， $\mathrm{O}_{3}$ の 発生は極めて多い，さらに，酸化生成物に関しても前者 では $98 \%$ 以上のベンゼンが CO と $\mathrm{CO}_{2}$ マ酸化される が, 後者では反応器前後の炭素の物質収支が取れておら ず，炭素の析出や粒子状物質の生成が危惧されている.

\section{1 .3 研究の方向性}

これまでに, 最適な反応器およびその操作条件を得る に至っていないが，プラズマ操作因子によって反応器の

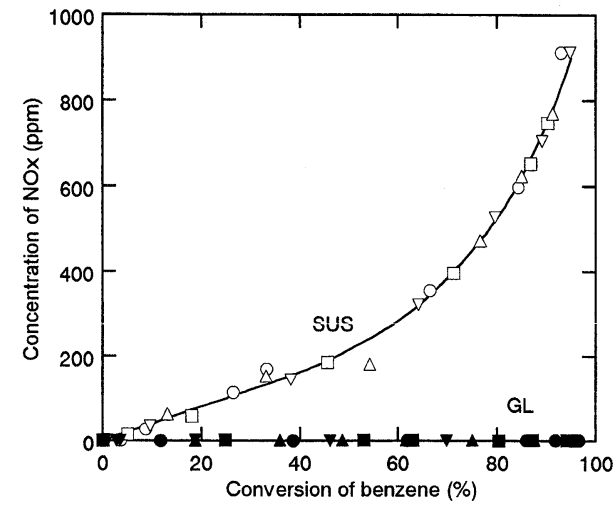

Fig. 4 Behavior of NOx formation as a function of benzene conversion.

特性が大きく変わることを理解していただけたと思う。 今後, 反応系に適した放電方式を選択するためにも， ㅇ ックトベッド式放電以外の沿面放電，無声放電，パルス 放電，あるいはこれらを複合させた方式についてその特 性を詳細に整理し，系統的に情報を蓄積していくことが 必要不可欠である.

\section{2 他の技術との複合化}

プラズマ法の問題点を解決するもら一つの手法とし て，他の技術との組み合わせが試みられている，その中 でも触媒との組み合わせが比較的良く調べられている。 その組み合わせ法にも大きく一段式と多段式の二通りの 方法があるが，ここではシステムをシンプルにするため 一段で触媒法と組み合わせた事例を紹介する。ここで紹 介するパックトベッド反応器は, 他の反応器と比べて触 媒との組反合わせが容易であることが知られている15).

3.2.1 副生成物の発生抑制を目指して（低温プラズ マ之触媒の複合化) ${ }^{19)}$

パックトベッド反応器内に充填する強誘電体と触媒を 物理的に混合することにより低温プラズマと触媒の複合 化を行った ${ }^{19)}$ ．強誘電体の久で充填されている従来型反 応器と触媒複合型反応器を用い，一定時間 (30分間) の 放電で生成した全 $\mathrm{COx}$ 量の相対比（従来型基準）， そ の中の $\mathrm{CO}_{2}$ 選択率, 及び $\mathrm{N}_{2} \mathrm{O}$ 量の相対比を Table 2 に 示す。この結果, アルミナや触媒を複合させたほとんど の反応系で分解量（分解効率）が増加していることがわ かる、柰た， $\mathrm{CO}_{2}$ 選択率についてはアルミナを用いる ことで従来型よりも改善されるが，金属活性種を担持し たものではさらにプラスの効果が認められた。同時に， 放電副生成物の $\mathrm{N}_{2} \mathrm{O}$ 発生も抑制され, $\mathrm{CO}_{2}$ 選択率同 様，触媒ごとにその効果が異なることも明らかになった。 
Table 2 Products (byproducts) for the decomposition of benzene using the hybrid reactors at $6.0 \mathrm{~W}$ of input power for $30 \mathrm{~min}$

\begin{tabular}{c|c|c|c|c}
\hline \hline \multirow{2}{*}{$\begin{array}{c}\text { Combined } \\
\text { pellets } \\
\text { with } \\
\mathrm{BaTiO}\end{array}$} & \multicolumn{2}{|c|}{$\begin{array}{c}\text { Relative ratio of products } \pm 1 \\
(\text { Total amount of formation } / \mathrm{mol})\end{array}$} & $\begin{array}{c}\text { 保 } \\
\text { Selectivity }\end{array}$ \\
\cline { 2 - 5 } None & $\begin{array}{c}1.0 \\
\left(2.4 \times 10^{-4}\right)\end{array}$ & $\begin{array}{c}1.0 \\
\left(3.1 \times 10^{-5}\right)\end{array}$ & $\begin{array}{c}1.0 \\
\left(1.8 \times 10^{-4}\right)\end{array}$ & 67 \\
\hline $\mathrm{Al}_{2} \mathrm{O}_{3}$ & 1.2 & 0.7 & 1.1 & $72-76$ \\
\hline $\mathrm{Ni} / \mathrm{Al}_{2} \mathrm{O}_{3}$ & 1.2 & 0.7 & - & 78 \\
\hline $\mathrm{Mo} / \mathrm{Al}_{2} \mathrm{O}_{3}$ & 1.1 & 0.6 & - & 74 \\
\hline $\mathrm{Rh} / \mathrm{Al}_{2} \mathrm{O}_{3}$ & 1.1 & 0.7 & - & 75 \\
\hline $\mathrm{Pt} / \mathrm{Al}_{2} \mathrm{O}_{3}$ & 1.2 & 0.7 & - & 76 \\
\hline $\mathrm{Pd} / \mathrm{Al}_{2} \mathrm{O}_{3}$ & 1.0 & 0.7 & - & 76 \\
\hline $\mathrm{Cu} / \mathrm{Al}_{2} \mathrm{O}_{3}$ & 1.2 & 0.6 & - & 76 \\
\hline $\mathrm{Ag} / \mathrm{Al}_{2} \mathrm{O}_{3}$ & 1.2 & 0.6 & - & 76 \\
\hline $\mathrm{Co} / \mathrm{Al}_{2} \mathrm{O}_{3}$ & 1.1 & 0.7 & - & 78 \\
\hline $\mathrm{MS}-3 \mathrm{~A}$ & 2.1 & 1.1 & 0.8 & 63 \\
\hline $\mathrm{MS}-4 \mathrm{~A}$ & 1.7 & 1.0 & 0.6 & 61 \\
\hline $\mathrm{MS}-5 \mathrm{~A}$ & 1.7 & 1.0 & 0.6 & 63 \\
\hline $\mathrm{MS}-13 \mathrm{X}$ & 1.4 & 0.9 & 0.6 & 74 \\
\hline
\end{tabular}

3.2.2 電力効率の向上を目指して（低温プラズマと 吸着剂の複合化 $)^{20)}$

一方, VOGs 分解率は, 反応ガス中に含まれる VOCs の濃度が低いほど高くなることが知られている。しか し, 電力効率 (単位当たりの投入エネルギー当たりに分 解可能な VOCs 量）は逆に高濃度の方が高い9)，低濃度 の VOCs を吸着剂等で濃縮することにより電力効率が 向上することが期待されたので，触媒の代わりに吸着能 力の高いゼオライト（モレキュラーシーブ：MS）を複 合化したパックトベッド反応器で希薄濃度ベンゼンのプ ラズマ分解反応を行った ${ }^{20)}$. 反応に先だち, ゼオライト に気相ベンゼンを充分吸着させた後, 放電を開始した。 その結果, ゼオライトを用いた反応器で従来型よりも COx 生成量（ベンゼン分解量）が多く（Table 2)，そ の值は気相ベンゼンが全て分解酸化したときに生じる理 論 $\mathrm{COx}$ 量を超えていることから，気相中だけでなくゼ オライト上に濃縮されたベンゼンもプラズマ分解を受 け，電力効率が向上することが明らかになった．同時 に, 窒素酸化物 (NOx) の発生抑制も観測された。

\section{2 .3 研究の方向性}

近年, この他にも一段式の複合化法では，光触媒では
知られている $\mathrm{TiO}_{2}$ を組み合わせた反応器 ${ }^{21-24)}$ や電極に 異なる金属材料を用いた反応器25)でも VOGs 分解に対 して触媒効果が発現することが報告されている.

一方，プラズマ反応器の前後に他の技術を組み合わせ ることは比較的容易であるため多段式の方法も検討され ている，例えば，上流側にプラズマ反応器（無声放電） をその下流に触媒層（常温）を配置することにより，シ ステムの前段で主に高濃度の $\mathrm{O}_{3}$ を発生させ，後段の触 媒上でその $\mathrm{O}_{3}$ の分解により生じる酸素活性種を利用し て VOCs を分解する手法である ${ }^{26,27)}$ 。この他に，NOx 処理の目的ではあるが, プラズマ反応器の下流にケミカ ルプロセスを組み合わせた方法（多段式）なども報告さ れている28).

これらの方法はそれぞれ一長一短があり，組み合わせ 手法の優劣はつけがたいが，他の技術との組み合わせが プラズマ法の高度化に対し極めて重要であることがわか る.

\section{4.おわりに}

現在までに揮発性有機化合物対策に拉ける最適なプラ ズマ反応器及びその操作条件については明らかになって いないが，副反応を最小限に抑光，より望ましい生成物 へ高い効率で酸化する技術を確立するためには, 同じ反 応条件の下, 複数の手法でプラズマ反応を系統的に比 較・検討し，それぞれの長所・短所を明白にしなければ ならない. 特に, 後半に紹介した他の技術との連携を考 慮する上でも，それにあった操作条件等の設定は必要不 可欠であろう.

最後に，本解説が実用化へ向けた低温プラズマ技術の 開発に少しでも敃役に立てれば幸いである.

\section{[文献〕}

1) T. Yamamoto, P. A. Lowless, M. K. Owen and D. S. Ensor: NATO ASI Series, 34, part B (1993) 223.

2) C. N. Nunez, G. H. Ramsey, W. H. Ponder and J. H. Abott: Air \& WASTE, 43 (1993) 242.

3) H. Kohno, A. A. Berezin, J. S. Chang, T. Yamamoto, A. Shibuya and S. Honda: IEEE Trans. Ind. Applcat., 34 (1998) 953.

4) S. Futamura and T. Yamamoto: IEEE Trans. Ind. Appl., 33 (1997) 447.

5) T. Yamamoto, K. Mizuno, I. Tamori, A. Ogata, M. Nifuku, M. Michalska and G. Prieto: IEEE Trans. Ind. Applcat., 32 (1996) 100.

6) T. Oda, R. Yamashita and T. Takahashi: IEEE Trans. Ind. Applcat., 32 (1996) 227.

7) T. Oda, R. Yamashita, K. Tanaka, T. Takahashi and S. Masuda: IEEE Trans. Ind. Applcat., 32 (1996) 1044. 
8) T. Yamamoto, J. S. Chang, A. A. Berezin, H. Kohno, S. Honda and A. Shibuya: J. Adv. Oxid. Technol., 1 (1996) 67.

9) A. Ogata, N. Shintani, K. Mizuno, S. Kushiyama and T. Yamamoto: IEEE Trans. Ind. Applcat., 35 (1999) 753.

10）新版 静電気ハンドブック (静電気学会編), オー 么社, 東京, 1998, p. 28.

11) A. Mizuno, Y. Yamazaki, H. Ito and H. Yoshida: IEEE Trans. Ind. Applicat., 28 (1992) 535.

12) 尾形 敦 : 静電気学会誌, 24 (2000) 29.

13) 伊藤泰郎: 静電気学会誌, 21 (1997) 2.

14）小田哲治 : 静電気学会誌, 19 (1995) 283.

15）水野 彰：静電気学会誌, 19 (1995) 289.

16) 山本俊昭: 静電気学会誌, 19 (1995) 301.

17) R. Hackam and H. Akiyama: IEEE Trans. Dielectr. Insul., 7 (2000) 654 .

18) A. Ogata. K. Miyamae, K. Mizuno, S. Kushiyama and M. Tezuka: Plasma Chem. Plasma Process., 22 (2002) 537.

19) A. Ogata, K. Yamanouchi, K. Mizuno, K. Kushiya- ma and T. Yamamoto: IEEE Trans. Ind. Applicat., 35 (1999) 1289.

20) A. Ogata, D. Ito, K. Mizuno, S. Kushiyama and T. Yamamoto: IEEE Trans. Ind. Applcat., 37 (2001) 959.

21) M. Kang, B.-J. Kim, S. M. Cho, G.-H. Chung, B.-W. Kim, G. Y. Han and K. J. Yoon: J. Mol. Catal. A, 180 (2002) 125.

22) T. Oda, T. Takahashi and S. Kohzuma: IEEE Trans. Ind. Applicat., 37 (2001) 965.

23）永長久寛, 椛島 一, 二夕村森: 静電気学会誌, 26 (2002) 228.

24) D. Li, D. Yakushiji, S. Kanazawa, T. Ohkubo and Y. Nomoto: J. Electrostat., 55 (2002) 311.

25) X. Chen, J. Rozak, J.-C. Lin, S. L. Suib, Y. Hayashi and H. Matsumoto: Appl. Catal. A, 219 (2001) 25.

26) K.-P. Francke, H. Miessner and R. Rudolph: Plasma Chem. Plasma Process., 20 (2000) 393.

27) H. Einaga, T. Ibusuki and S. Futamura: IEEE Trans. Ind. Applcat., 37 (2001) 1476.

28) T. Yamamoto, C. L. Yang, M. Beltran and Z. Kravets: IEEE Trans. Ind. Applcat., 36 (2000) 923. 